\title{
Diabetes and pregnancy
}

\author{
Authors: Emma G Wilmot ${ }^{A}$ and Peter Mansell ${ }^{B}$
}

An increasing number of women who are pregnant have diabetes, whether gestational or pre-existing. Diabetes in pregnancy is associated with a number of adverse outcomes including birth trauma, neonatal hypoglycaemia, macrosomia and pre-eclampsia. Those with pre-existing diabetes have the additional risks which include congenital defects and increased perinatal mortality. This paper summarises the complications of diabetes in pregnancy and highlights some of the recent controversy surrounding the diagnosis of gestational diabetes.

\section{Introduction}

An increasing number of pregnancies are complicated by diabetes, whether type 1 diabetes (T1DM), type 2 diabetes (T2DM) or gestational diabetes (GDM), all of which are associated with an increased risk of adverse outcomes. ${ }^{1}$ Following the introduction of insulin in the 1920s, women with T1DM experienced a perinatal mortality rate of around $40 \% .^{2}$ Improvements in diabetes care have led to a substantial reduction in adverse outcomes but unfortunately, when compared with the general population, the risks remain elevated in all forms of diabetes in pregnancy. Maternal T1DM and T2DM are associated with a four-fold increased risk of congenital malformations and other serious complications (a list of the more frequent complications is provided in Table 1), whereas the milder degrees of hyperglycaemia found in GDM are associated with complications that include macrosomia, birth trauma and maternal pre-eclampsia. ${ }^{3}$ This paper aims to provide the general physician with insight into some of the key issues related to diabetes in pregnancy: an understanding of some the potential medical issues that may arise; awareness of the recent controversies related to diagnosing GDM; and an understanding of how outcomes might be further improved in the future.

\section{Medical issues}

Antenatal diabetes care involves intensive multidisciplinary support to help women optimise their glycaemic control and minimise the risks of complications in pregnancy. There are two main areas of this care that are particularly relevant to physicians: hypoglycaemia and diabetic ketoacidosis (DKA).

Authors: ${ }^{A}$ consultant diabetologist, Royal Derby Hospital, Derby, UK; ${ }^{\text {B }}$ consultant physician, Queen's Medical Centre, Nottingham, UK

\section{Glucose control and hypoglycaemia}

Maintaining glucose levels as close to normal as possible is the cornerstone of diabetes antenatal care. For women with pre-existing diabetes, this is particularly crucial during organogenesis in the first trimester; hyperglycaemia during this period substantially increases the risk of miscarriage, congenital defects and perinatal mortality. ${ }^{4}$ Tight glycaemic control can minimise these risks to nearly those of nondiabetic women, and National Institute for Health and Care Excellence (NICE) recommend aiming for a glycated haemoglobin (HbAlc) of less than $43 \mathrm{mmol} / \mathrm{mol}$ (6.1\% of total haemoglobin). ${ }^{5}$ Achieving normoglycaemia in diabetes is challenging. If achieving tight control proves difficult despite supported intensive multiple daily injections of insulin and structured group education, then insulin pump therapy is an option for women with T1DM. Insulin pump therapy reduces the variation in insulin absorption, leading to more flexible and accurate insulin delivery. This results in better or comparable glycaemic control and pregnancy outcomes with no greater, or possibly reduced, risk of maternal hypoglycaemia. ${ }^{6-8}$ Owing to the potential risk of temporary deterioration in glucose control and ketoacidosis, this therapy is ideally initiated pre-conceptually and not during pregnancy. ${ }^{9}$ The quest for normoglycaemia, combined with the physiological fluctuations in insulin sensitivity during the anteand post-natal period, can increase the frequency and/or severity of hypoglycaemia. The first trimester, post-delivery and breast feeding are associated with a reduction in insulin requirements, which again can increase the risk of hypoglycaemia. Severe hypoglycaemia occurs 3-5 times more frequently in the first trimester in women with T1DM and can occur before they know that they are pregnant. ${ }^{10}$ Insulin requirements tend to rise throughout the second and third trimesters and fall to pre-pregnancy levels at the time of delivery of the placenta. This requires an abrupt reduction in insulin doses to pre-pregnancy levels to avoid post-delivery hypoglycaemia. Breastfeeding can also reduce insulin requirements and is an additional risk factor for hypoglycaemia in women with insulin-treated diabetes. ${ }^{10}$ This complication can be avoided by adjustment of insulin dose and/or supplemental carbohydrate. Breast feeding should be encouraged in all women with diabetes, particularly as it reduces the child's future risk of both T1DM and T2DM. ${ }^{11}$

Women who are most at risk of severe hypoglycaemia in pregnancy are those with:

$>$ a history of severe hypoglycaemia in the preceding year

> impaired hypoglycaemia awareness 
Table 1. The complications of pre-existing diabetes in pregnancy.

$\begin{array}{ll}\text { Risk } & \text { Details } \\ \text { Maternal complications } & \begin{array}{l}\text { Risk of progression of existing disease during } \\ \text { Diabetic }\end{array} \\ \text { retinopathy } & \begin{array}{l}\text { and in the year following pregnancy. Regular } \\ \text { ophthalmological review is recommended }\end{array} \\ \begin{array}{ll}\text { Diabetic } \\ \text { nephropathy }\end{array} & \begin{array}{l}\text { Risk of progressive proteinuria in pregnancy in } \\ \text { addition to pre-term labour, IUGR and } \\ \text { preeclampsia }\end{array} \\ \text { Hypertension } & \begin{array}{l}\text { Increased risk of IUGR, preeclampsia, abruption } \\ \text { placenta and stroke }\end{array}\end{array}$

\section{Fetal complications}

Miscarriage Strong association with glucose control with rates ranging from normal when glucose control is excellent, to $44 \%$ when the $\mathrm{HbA} 1 \mathrm{c}$ is $>97 \mathrm{mmol} / \mathrm{mol}(11 \%)$

Birth defects Increase in the risk of birth defects of 4-8 fold, which is associated with pre-conception glycaemic control and includes congenital heart defects, neural tube defects, renal agenesis and caudal dysgenesis

IUGR Maternal hypertension, vascular disease, retinal and renal complications

Macrosomia Defined as a birth weight $>90$ th centile for gestational age or a birth weight $>4 \mathrm{~kg}$. Macrosomia occurs in $15-45 \%$ of babies born to women with diabetes, a 3-fold increase when compared with normoglycaemic controls. Obesity is a strong and independent risk factor, so tight glucose control may not necessarily prevent macrosomia. Macrosomia increases the risk of birth injury, including shoulder dystocia and brachial plexus trauma

Perinatal Includes neonatal jaundice (29-55\%), morbidity hypoglycaemia (9-29\%), respiratory distress (3-8\%), and transient tachypnoea (2-4\%)

Perinatal Two-fold increased risk compared with the mortality general population. Overall, the risk has reduced 30 -fold since the introduction of insulin in the 1920 s

Adult health Children whose mothers had diabetes during their pregnancy have a heightened future risk of obesity, metabolic syndrome, dysglycaemia and diabetes

IUGR = intrauterine growth restriction.

$>$ a longer duration of diabetes

$>$ low HbAlc in early pregnancy

$>$ fluctuating plasma glucose levels

$>$ excessive use of supplementary insulin between meals.

Hypoglycaemia is generally without risk for the fetus as long as the mother avoids injury during the episode. In the event of more than one episode of severe hypoglycaemia (requiring third-party

\section{Box 1. Risk factors for gestational diabetes.}

\section{Risk factors for gestational diabetes}

Body mass index in the obese range (above $30 \mathrm{~kg} / \mathrm{m}^{2}$ )

Previous macrosomic baby weighing $4.5 \mathrm{~kg}$ or above

Previous gestational diabetes

Family history of diabetes (first-degree relative with diabetes)

Ethnicity: South Asian, Black Caribbean, Middle Eastern

assistance) in one year, or the complete loss of hypoglycaemiawarning symptoms, the patient must not drive and needs to inform the Driver and Vehicle Licensing Agency of her condition.

\section{Diabetic ketoacidosis}

DKA in pregnancy is a serious condition associated with greatly increased perinatal morbidity and mortality. A high index of suspicion is required because DKA can develop insidiously and, with the higher glomerular filtration rate and lower renal threshold for glycosuria in pregnancy, often at lower blood glucose levels than typically seen outside of pregnancy, even below $10 \mathrm{mmol} / \mathrm{l}^{12}$ Patients must be educated about the precipitating causes (which include infection, vomiting, inappropriate insulin management and insulin pump failure), the availability of blood ketone monitoring, early recognition, and the need for immediate referral to the diabetes antenatal team to prevent further deterioration.

\section{Controversies surrounding gestational diabetes}

The obesity epidemic, combined with advancing maternal age, has driven an increase in the prevalence of GDM. ${ }^{13} \mathrm{GDM}$ is defined as 'degrees of maternal hyperglycaemia less severe than those found in overt diabetes but associated with an increased risk of adverse pregnancy outcomes'. Using traditional diagnostic criteria, GDM complicates $2-6 \%$ of pregnancies and is associated with macrosomia, neonatal hypoglycaemia and maternal pre-eclampsia. ${ }^{2}$ Intervention trials have shown that the recognition of GDM and its management with diet, physical activity, home blood-glucose monitoring, metformin and/or insulin are effective in improving clinical outcomes, although the number of patients needed to treat to prevent one adverse outcome is $34 .{ }^{1,5,14}$ Recent controversial international recommendations have changed the blood-glucose threshold used to diagnose GDM, which could have significant implications for both clinical practice and society.

Traditionally, women with risk factor(s) for GDM (Box 1) were offered a screening $75 \mathrm{~g}$ oral glucose tolerance test (OGTT) at 24-28 weeks of pregnancy. ${ }^{5}$ However, in 2008, the Hyperglycaemia and Adverse Pregnancy Outcomes (HAPO) trial confirmed a continuous linear relationship between both fasting and post-OGTT levels of glycaemia and adverse outcomes of pregnancy, extending well below the $\geq 7.0 \mathrm{mmol} / \mathrm{l}$ fasting glucose level recommended by the World Health Organisation (WHO) in 1999 for the diagnosis of GDM. ${ }^{1,5}$ This prompted the International Association of Diabetes and Pregnancy Study Groups (IADPSG) to revise the recommendations for diagnosing GDM. ${ }^{15}$ They 


\section{Key points}

> In pregnancy, pre-existing maternal diabetes (type 1 and type 2) is associated with an increased risk of congenital malformations; both pre-existing and gestational diabetes are associated with an increased risk of adverse outcomes including macrosomia (birth weight $>4,000 \mathrm{~g}$ ), caesarean section and shoulder dystocia

> Adverse outcomes in pregnancies complicated by diabetes are related to glycaemic control

> Tight glycaemic control improves outcomes in pregnancies complicated by diabetes but this can increase the risk of hypoglycaemia in insulin-treated women, particularly in the first trimester and immediately post-delivery

> There is no universal consensus on the diagnostic criteria for gestational diabetes; updated National Institute for Health and Care Excellence (NICE) guidance on diabetes in pregnancy is awaited

> Type 2 diabetes is often asymptomatic; screening in early pregnancy has been recommended, especially in high-risk groups

KEYWORDS: Pregnancy, diabetes, gestational diabetes, teratogen, International Association of the Diabetes and Pregnancy Study Groups (IADPSG)

recommended that all women, not just those with risk factors, undergo a $75 \mathrm{~g}$ OGTT at 24-28 weeks gestation and that the diagnosis of GDM is made on the basis of one or more abnormal plasma glucose results: fasting $\geq 5.1 \mathrm{mmol} / \mathrm{l}, 1$ hour $\geq 10 \mathrm{mmol} / \mathrm{l}$ or 2 hour $>8.5 \mathrm{mmol} / \mathrm{l}$. This recommendation is based on a 1.75 -fold increase in the risk of large for gestational age, cord c-peptide $>90$ th centile and $\%$ newborn body fat $>90$ th centile compared to the lowest glucose values in the HAPO study. These criteria, if adopted, could lead to a 2-3-fold increase in the prevalence of GDM diagnoses. ${ }^{16}$

The IADPSG recommendations, which were made on the basis of observational data rather than interventional trials, have been controversial and hence criticised. ${ }^{16}$ A summary of the guidance and the main advantages and disadvantages of these criteria are presented in Table 2. The controversy is reflected in current UK practice with different centres using different criteria for diagnosis and treatment targets in their local population. A UKwide standardised approach would be advantageous; NICE is currently reviewing the diabetes in pregnancy guidelines, which will hopefully provide some clarity on this issue.

\section{Future directions}

Pre-conception care, acknowledged as a NICE quality standard for diabetes, is associated with improved outcomes (see Table 3).${ }^{17}$ However, few women, particularly those with T2DM,

Table 2. IADPSG recommendations for the diagnosis

of gestational diabetes.

\section{WHO 1999}

High risk (see Table 2)

Screening population

Fasting

1 hour

2 hour $\geq 7.0 \mathrm{mmol} / \mathrm{l}$

$\geq 7.8 \mathrm{mmol} / \mathrm{l}$

IADPSG

Universal

\section{IADSPG advantages}

> Diagnostic level set at the level of glucose at which key pregnancy outcomes occurred: large for gestational age, cord c-peptide $>90$ th centile, $\%$ newborn body fat $>90$ th centile

$>$ All women undergo screening, compared with selective screening that misses nearly half of cases

$>$ Effective treatment available for gestational diabetes (Australian Carbohydrate Intolerance Study in Pregnant Women trial $^{14}$ )

\section{IADSPG disadvantages}

$>$ Criteria increase prevalence of gestational diabetes from 2-6\% to $18 \%$, which will have significant resource implications

$>$ Criteria are based on observational data

> Diagnosis is based on one abnormal glucose value, which is known to have poor reproducibility

> Concern about the psychological burden of screening, false positives and the medicalisation of previously healthy pregnancies

IADPSG = International Association of Diabetes and Pregnancy Study Groups; WHO = World Health Organisation.

access pre-conception care, and the challenge for the future will be ensuring that women are aware of and engage with their local services. ${ }^{3}$ An additional concern is the increase in the number of young women who have undiagnosed T2DM, largely driven by the obesity epidemic. Up to $5 \%$ of high-risk UK adults $<40$ years of age have undiagnosed T2DM, which, in the context of pregnancy, will increase the risk of congenital malformations. ${ }^{18}$ Universal testing with a fasting glucose $(\geq 7 \mathrm{mmol} / \mathrm{l})$ or $\mathrm{HbAlc}$ ( $\geq 48 \mathrm{mmol} / \mathrm{mol}, 6.5 \%$ ) at the first prenatal visit has been recommended but is not yet standard practice in the UK. ${ }^{9,15}$ Even if implemented, this approach may fail to protect the fetus from hyperglycaemia during organogenesis in those with undiagnosed diabetes. NICE have recommended screening for T2DM in all high-risk individuals who are younger than 40 years of age. 'High risk' includes black and minority ethnic groups, and those with other risk factors including obesity, hypertension, mental health illness and admission to emergency medical admissions units, amongst others. ${ }^{19}$ If this guidance is implemented nationally, then it may go some way to improving the outcomes in pregnancies complicated by T2DM.

\section{Conclusion}

Diabetes in pregnancy is increasingly common. Pre-existing diabetes in pregnancy is associated with substantial risks, which can be minimised through effective pre-conceptual, antenatal and self-management. Significant controversy exists regarding the 
Table 3. Pre-conception care.

\begin{tabular}{|c|c|}
\hline e-conception care & Detail \\
\hline Tight glycaemic control & $\begin{array}{l}\text { Women planning pregnancy should aim for a } \mathrm{HbA} 1 \mathrm{c} \text { of less than } 6.1 \% \text {, with personalised glucose targets; } \\
\text { women with an } \mathrm{HbA} 1 \mathrm{c}>10 \% \text { are strongly advised to delay pregnancy as the risk of congenital malformation } \\
\text { is in the order of } 10 \% .^{5}\end{array}$ \\
\hline High-dose folic acid & $\begin{array}{l}\text { lomen with diabetes are recommended to take high-dose }(5 \mathrm{mg}) \text { folic acid } 3 \text { months before contraception is } \\
\text { iscontinued. }\end{array}$ \\
\hline $\begin{array}{l}\text { Retinopathy } \\
\text { and manage }\end{array}$ & $\begin{array}{l}\text { Established retinopathy can deteriorate and progress rapidly during pregnancy and women with retinopathy } \\
\text { are counselled regarding this. }{ }^{9} \text { Women with retinopathy are reviewed and treated (if appropriate) by an } \\
\text { ophthalmologist prior to conception to minimise the potential risk of sight loss. }\end{array}$ \\
\hline Nephropathy care & $\begin{array}{l}\text { Pre-conception care includes screening for nephropathy, which includes a measure of microalbuminuria and } \\
\text { renal function. If serum creatinine is abnormal ( } 120 \mu \mathrm{mol} / \mathrm{l} \text { or more) or the estimated glomerular filtration rate } \\
\text { (eGFR) is less than } 45 \mathrm{ml} / \mathrm{min} / 1.73 \mathrm{~m}^{2} \text {, referral to a nephrologist is considered before discontinuing contraception. }\end{array}$ \\
\hline Cardiovasce & $\begin{array}{l}\text { The presence or development of cardiovascular disease during pregnancy carries substantial risks for the } \\
\text { mother and fetus with mortality rates of } 11 \% \text { and } 9 \% \text {, respectively, reported. }{ }^{9} \text { Those with cardiovascular risk } \\
\text { factors, a long duration of diabetes and/or older age may require a clinical assessment for the presence of } \\
\text { cardiovascular disease and further investigation. }\end{array}$ \\
\hline Stop & $\begin{array}{l}\text { Some women with diabetes take angiotensin-converting enzyme (ACE) inhibitors or angiotensin receptor } \\
\text { blockers for the treatment of hypertension or microalbuminuria and nephropathy. These agents can be } \\
\text { teratogenic, causing renal agenesis or dysgenesis in addition to intrauterine growth retardation in the second } \\
\text { and third trimesters. }{ }^{9} \text { They should be stopped prior to conception. Safer alternatives for those requiring } \\
\text { treatment for hypertension include methydopa, labetolol, diltiazem, clonidine and prazosin. }{ }^{9} \text { The safety of } \\
\text { statin therapy is uncertain and statins should be stopped } 3 \text { months prior to conception. }{ }^{9}\end{array}$ \\
\hline General lifestyle & $\begin{array}{l}\text { As with all pregnancies, it is also important to discuss maintaining or achieving a health body mass index, } \\
\text { smoking cessation and alcohol intake in the pre-conception setting. }\end{array}$ \\
\hline
\end{tabular}

optimal approaches to both the screening and diagnosis of GDM and UK NICE guidance on this matter is eagerly awaited.

\section{References}

1 HAPO Study Cooperative Research Group. Hyperglycemia and adverse pregnancy outcomes. N Engl J Med 2008;358:1991-2002.

2 Essex NL, Pyke DA, Watkins PJ, Brudenell JM, Gamsu HR. Diabetic pregnancy. Br Med J 1973;4:89-93.

3 Confidential Enquiry into Maternal and Child Health (CEMACH). Diabetes in pregnancy: are we providing the best care? Findings of a national enquiry: England, Wales and Northern Ireland. London: CEMACH, 2007.

4 Bell R, Glinianaia SV, Tennant PW, Bilous RW, Rankin J. Periconception hyperglycaemia and nephropathy are associated with risk of congenital anomaly in women with pre-existing diabetes: a population-based cohort study. Diabetologia 2012;55:936-47.

5 National Institute for Health and Clinical Excellence. NICE clinical guideline 63: Diabetes in pregnancy. Management of diabetes and its complications from pre-conception to the postnatal period. London: NICE, 2008. Available online at www.nice.org.uk/nicemedia/pdf/ CG063Guidance.pdf [Accessed 20 October 2014].

6 Pickup JC. Insulin-pump therapy for type 1 diabetes mellitus. $N$ Engl J Med 2012;366:1616-24.

7 Misso ML, Egberts KJ, Page M, O'Connor D, Shaw J. Continuous subcutaneous insulin infusion (CSII) versus multiple insulin injections for type 1 diabetes. Cochrane Database Syst Rev 2010;1:CD005103.

8 Mukhopadhyay A, Farrell T, Fraser RB, Ola B. Continuous subcutaneous insulin infusion vs intensive conventional insulin therapy in pregnant diabetic women: a systematic review and metaanalysis of randomized, controlled trials. Am J Obstet Gynecol 2007;197:447-56.

9 Blumer I, Hadar E, Hadden DR et al. Diabetes and pregnancy: an endocrine society clinical practice guideline. J Clin Endocrinol Metab 2013;98:4227-49.
10 Seaquist ER, Anderson J, Childs B et al. Hypoglycemia and diabetes: a report of a workgroup of the American Diabetes Association and the Endocrine Society. Clin Endocrinol Metab 2013;98:1845-59.

11 Gouveri E1, Papanas N, Hatzitolios AI, Maltezos E. Breastfeeding and diabetes. Curr Diabetes Rev 2011;7:135-42.

12 Sibai BM, Viteri OA. Diabetic ketoacidosis in pregnancy. Obstet Gynecol 2014;123:167-78.

13 Ferrara A. Increasing prevalence of gestational diabetes mellitus: a public health perspective. Diabetes Care 2007;30:S141-6.

14 Crowther CA, Hiller JE, Moss JR et al. Effect of treatment of gestational diabetes mellitus on pregnancy outcomes. $N$ Engl J Med 2005;352:2477-86.

15 Metzger BE, Gabbe SG, Persson B et al. International association of diabetes and pregnancy study groups recommendations on the diagnosis and classification of hyperglycemia in pregnancy. Diabetes Care 2010;33:676-82.

16 Cundy T, Ackermann E, Ryan EA. Gestational diabetes: new criteria may triple the prevalence but effect on outcomes is unclear. BMJ 2014;348:g1567.

17 National Institute for Health and Clinical Excellence. Diabetes in adults quality standards. London: NICE, 2011. Available online at http://guidance.nice.org.uk/QS6 [Accessed 20 October 2014].

18 Wilmot EG, Edwardson CL, Biddle SJ et al. Prevalence of diabetes and impaired glucose metabolism in younger 'at risk' UK adults: insights from the STAND programme of research. Diabet Med 2013;30:671-5.

19 National Institute for Health and Clinical Excellence. Preventing Type 2 diabetes: risk identification and interventions for individuals at high risk. London: NICE, 2012. Available online at www. nice.org.uk/guidance/PH38 [Accessed 20 October 2014].

Address for correspondence: Dr EG Wilmot, Royal Derby Hospital, Uttoxeter Road, Derby DE22 3NE, UK.

Email: emma.g.wilmot@gmail.com 